Received $15^{\text {th }}$ April 2020 Accepted $30^{\text {th }}$ July 2020

Link to DOI:

10.25220/WNJ.V04.i1.0003

Journal Website: www.worldnutrijournal.org

\section{Effect of carnitine on patients with heart failure: an evidence-based case report}

\author{
Yosua Y Kristian ${ }^{1}$, Wiji Lestari ${ }^{1}$ \\ 1. Department of Nutrition, Faculty of Medicine, Universitas Indonesia, Dr. Cipto Mangunkusumo \\ Hospital, Jakarta, Indonesia.
}

\begin{abstract}
Background: Heart disease is one of the leading causes of death in Indonesia. Nutritional management plays an important role in overcoming heart disease, both as prevention and treatment. Carnitine plays a role in fat metabolism and can reduce the formation of thrombosis, resulting in improved heart function and quality of life of patients.

Objectives: This study is aimed to identify the effect of carnitine in patients with heart failure. Methods: Existing research findings and articles are selected based on inclusion and exclusion criteria in three databases, namely PubMed, Cochrane and Wiley. The outcome were functional capacity and heart function.

Results: One meta-analysis that address with the clinical questions was obtained, and based on that article, giving carnitine to patients with heart failure has effects on increasing functional capacity, heart function, BNP serum and NT-proBNP levels. However, no effects found on mortality. Furthermore, no significant side effects on carnitine was found.

Conclusions: Carnitine supplementation at a dose of 1 up to $6 \mathrm{~g} /$ day has a positive impact on functional capacity, heart function, BNP serum and NT-proBNP levels in patients with heart failure, alongside with minimal side effects.
\end{abstract}

Keywords carnitine, heart failure, outcome

\section{Clinical scenario}

Mr. S, age 50, was admitted to the emergency room with the chief complaint of shortness of breath for the last 3 days, which would arise suddenly and became worse when in a sleeping position. History of diabetes was denied, however he had a history of high blood pressure for the past one year and was not taking medications regularly. Physical examination

\section{Corresponding author:}

Yosua Yan Kristian, MD

Department of Nutrition, Faculty of Medicine, Universitas Indonesia

Email:yosua.yankristian@gmail.com revealed cardiomegaly, normal heart sounds, no murmurs or gallops. Laboratory results: $\mathrm{Hb} 16$ $\mathrm{g} / \mathrm{dL}$, leukocytes $6500 / \mathrm{mm} 3$, platelets $230,000 / \mathrm{uL}$, LDL $243 \mathrm{mg} / \mathrm{dL}$, triglycerides $267 \mathrm{mg} / \mathrm{dL}$, uric acid $10 \mathrm{mg} / \mathrm{dL}$, troponin I $0.29 \mathrm{ng} / \mathrm{mL}$, BNP $312 \mathrm{pg} / \mathrm{mL}$. Electrocardiography test showed an enlarged left ventricle. The patient's body weight was $65.7 \mathrm{~kg}$, with a height of $160 \mathrm{~cm}$, and a body mass index of $25.6 \mathrm{~kg} / \mathrm{m} 2$. The patient was hospitalized and received treatment from internists and clinical nutrition specialists. Patient was diagnosed with obesity grade $1,{ }^{1}$ heart failure class 4 according to the New York Heart Association (NYHA), dyslipidemia, and hyperuricemia. Patient was given oral carnitine supplementation when discharged from the hospital at a dose of $1.5 \mathrm{~g} /$ day for 3 months 
period, and showed an improvement in NYHA class. Patient did not show any side effects after carnitine supplementation.

\section{Introduction}

Heart failure is a global problem with 26 million people worldwide and with 670,000 new cases found in America. Heart failure is the most common cause for hospital admittance in the United States and Europe. ${ }^{2}$ In Indonesia, heart failure prevalence is $5 \%$, with mortality rate up to $20 \%{ }^{3}$

One of the nutrients that has been found having an essential role for patients with heart failure is carnitine, which is an amino acid derivative that plays a role in fat metabolism and mitochondrial defence. Several studies have shown that carnitine, especially in the form of propionyl-L-carnitine, can reduce the accumulation of coronary artery thrombosis and embolism. Some sources of carnitine are milk and milk products, and red meat.

The role of carnitine in fat metabolism is as the transporter of acyl co-A into the mitochondrial matrix, so that fat can undergo $\beta$-oxidation and become a source of energy, especially for heart muscle cells. ${ }^{4}$ Healthy adult usually consume carnitine at a dose of $2-5 \mathrm{mg} / \mathrm{kgBW} /$ day. $^{5}$

Patients with heart failure often suffer from carnitine insufficiency due to reduced intake, malabsorption, and decreased muscle mass. Carnitine insufficiency results in reduced left ventricular diastolic function, reduced physical activity ability, and an increased risk of heart attack. ${ }^{7}$ However, carnitine has not yet been recommended as a routine therapy in patients with heart failure by the American College of Cardiology Foundation / American Heart Association (ACCF / AHA) ${ }^{8}$ Even so, giving carnitine can be a nutritional therapy for patients with heart failure that can help improve heart function and the quality of life of patients. Jing et al. ${ }^{9}$ carried out a research by administering carnitine intravenously twice a day for seven days, in the form of $1 \mathrm{~g}$ of L-carnitine dissolved in $100 \mathrm{~mL}$ of normal saline in patients with heart failure. The assessment was carried out on the NYHA class of patients. The results showed a $60.9 \%$ improvement in the NYHA class of intervention group, compared to the $44.7 \%$ improvement in the NYHA class of placebo group. A meta-analysis study of the effects of carnitine given orally in accordance with the needs of $3 \mathrm{~g}$ /day or more on mortality rate in patients with acute myocardial infarction did not show any significant impact. ${ }^{10}$

This evidence-based case report will discuss specifically about the effects of carnitine on patients with heart failure.

\section{Clinical questions}

P: Adult patients with heart failure

I: Carnitine

C: Without carnitine

O: Functional capacity and heart function

Clinical question: What is the effect of carnitine as a nutritional management on functional capacity and heart function in patients with heart failure?

\section{Methods}

Article Search Strategy

Existing research articles were generated from PubMed, Cochrane Library, and Wiley Online on December 12, 2019. Searching terminology is described in Table 1.

\section{Article Selection Strategy}

\section{Eligibility Criteria}

Screening is based on MesH Term, an assessment of conformity with PICO, and with inclusion and exclusion criteria. The inclusion criteria were 1 . Study subjects were adult patients (aged $\geq 18$ years old), 2. Subjects diagnosed with heart failure with various stages 3 . Clinical trials or meta-analysis with carnitine treatment 4 . Journals published in the last 5 years 5 . Tests clinically carried out in humans. Meanwhile, the exclusion criteria were 1. Journal is not written in English and 2. full text is not available.

\section{Method of critical appraisal}

All authors did the critical appraisal by using the method according to the Center of Evidence Based Medicine (www.cebm.net) for intervention studies that has been modified in Indonesian language.

\section{Findings}


Based on the results of the search from the database, and by assessing the inclusion and exclusion criteria, an article that is eligible to be included as a reference for critical review is used (Figure 1).

Selected articles are meta-analysis of clinical trials, with a total number of 1625 patients. The length of follow-up of the subject in the articles is from 7 days to 3 years. Carnitine given to patients with a dose of 1 to $6 \mathrm{~g}$ /day.

The articles obtained have a level of evidence 1, which is a meta-analysis of 17 clinical trials. Findings from articles used in this work illustrate that carnitine administration has a positive impact on functional capacity and heart function. The validity of the criteria can be seen in table 3 . The relevance of the criteria can be seen in table 4 .

There were no differences of mortality rate in patients with heart failure $(\mathrm{p}=0.08)$ and carnitine side effects $(p=0.83)$, there was an increase in functional capacity marked by a decrease in NYHA class $(p<0.01)$, decrease in BNP serum markers $(p=0.01)$ and NT-proBNP $(p<0.01)$, as well as increased cardiac function $(\mathrm{p}<0.01)$.

\section{Discussion}

Song $\mathrm{X}$ et al. conducted a meta-analysis study for the effects of carnitine supplementation on patients with heart failure with a search time limit until September 30, 2016. The study looked for randomized controlled literature from various databases, abstracts of scientific meetings, as well as manually from unpublished articles and studies. Based on the search, 17 appropriate journals were found, with a total of 1625 research subjects. Patients' age ranged between 43 and 78 years. Carnitine dosage given ranged from 1 to $6 \mathrm{~g} /$ day, and administered from 7 days to 3 years. Patients receiving carnitine were clasified as NYHA class IIIV, with a LVEF of $27 \%$ to $52 \%$ before the intervention.

Outcomes from this study showed that carnitine had a positive impact on the functional capacity, which is characterized by a decrease in NYHA class. ${ }^{11}$ The literature that has the greatest weight in the meta-analysis was the research conducted by Jing $\mathrm{ZC}$ et al. The study gave carnitine of $1 \mathrm{~g}$ intravenously, twice a day for seven days. The effectiveness of carnitine reached $60.7 \%$ compared to the control group of $44.7 \%(\mathrm{P}=0.012)$. The 6minute walk test did not show significant difference between control and intervention $(\mathrm{P}=0.14) .{ }^{9}$ The study from Song $\mathrm{X}$ et al. also showed that carnitine had positive effect on serum-BNP $(\mathrm{P}=0.01)$ and NT-proBNP $(\mathrm{P}=0.0003)$. Both BNP and NTproBNP can act as prognostic factors in patients with heart failure or in patients with asymptomatic left ventricular dysfunction. ${ }^{11}$

The heart function also showed significant improvement. The heart functions assessed were LVEF ( $\mathrm{P}<0.00001)$, SV $(\mathrm{P}<0.00001), \mathrm{CO}$ ( $\mathrm{P}$ $<0.00001), \mathrm{E} / \mathrm{A}$ ratio $(\mathrm{P}=0.0003), \operatorname{LVESD}(\mathrm{P}=$ $0.002)$ ), LVEDD ( $\mathrm{P}<0.0001)$, and LVESV $(\mathrm{P}=$ $0.01) .{ }^{11}$ The antioxidant effect of carnitine can prevent the formation of superoxide in heart muscle and excessive inflammation, which results in changes in heart structure. ${ }^{4}$

There was no impact on the mortality of patients with heart failure, both in intention to treat analysis and per protocol. From a total of ten literature, six literatures showed no side effects of carnitine administration in patients with heart failure, while four studies report side effects such as dry mouth and gastrointestinal disorders. One literature reported that there was skin rash as a side effect, but it did occur in both treatments, both the control group and the intervention group. ${ }^{11}$

Based on the article in this evidence-based case report, it can be concluded that administration of carnitine can improve the quality of life of patients with heart failure, improve heart function and serum levels of BNP and NT-proBNP, with minimal side effects. Carnitine can be given orally by using carnitine supplements, and using food sources. Examples of food sources of carnitine are beef, with carnitine of $2320 \mathrm{mg} / \mathrm{kg}$ dry weight, duck meat with carnitine $732 \mathrm{mg} / \mathrm{kg}$ dry weight, skim milk with carnitine $400 \mathrm{mg} / \mathrm{kg}$ dry weight, condensed milk 396 $\mathrm{mg} / \mathrm{kg}$ dry weight, and yogurt $142-139 \mathrm{mg} / \mathrm{kg}$ dry weight.

\section{Recommendation:}

Patients with heart failure can be given carnitine at least $1 \mathrm{~g}$ /day to $6 \mathrm{~g}$ /day. In administration of carnitine at a dose of $1 \mathrm{~g}$, it can be given for 1 year, a dose of $1.5 \mathrm{~g}$ carnitine with a duration of 3 months, while a dose of $3 \mathrm{~g}$ and $6 \mathrm{~g}$ can be given for 7 days 


\section{Conclusion}

Patients included in defined clinical scenario can be given carnitine up to $6 \mathrm{~g} / \mathrm{day}$, in the form of supplementation or derived from food sources such as milk, milk products, or meat. Giving carnitine can improve the quality of life of patients, heart function, reduce BNP serum and NT-proBNP levels, with minimal side effects. Giving carnitine has no impact on the mortality of patients with heart failure.

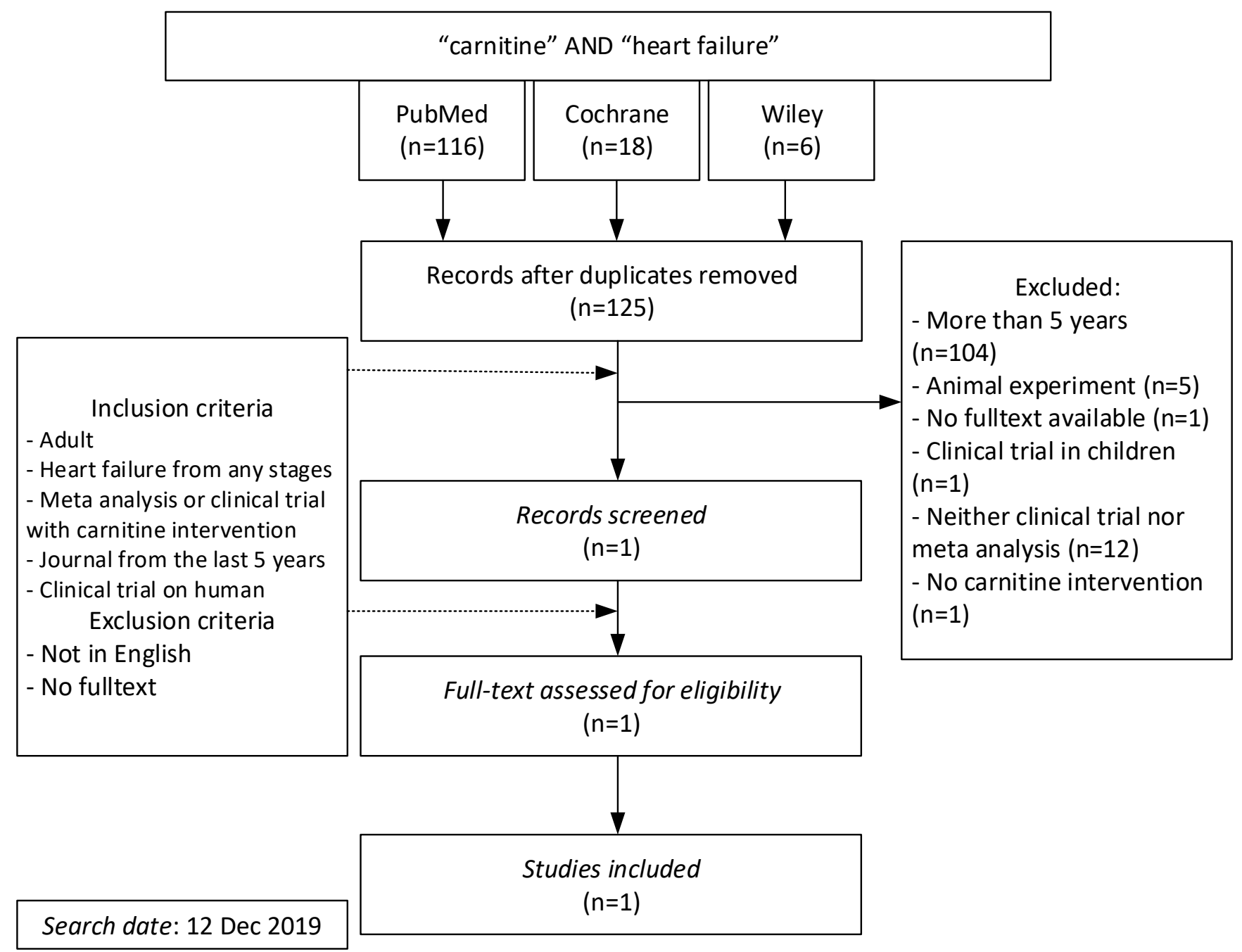

Figure 1. PRISMA flow chart 
Table 1. Terminology

\begin{tabular}{|c|c|c|c|c|}
\hline Database & \multicolumn{2}{|l|}{ Terminology } & Hits & Eligible \\
\hline PubMed & \multicolumn{2}{|c|}{$\begin{array}{l}(((\text { carnitine}[\mathrm{MeSH} \text { Terms]) OR carnitine[Title])) AND ((heart failure[MeSH } \\
\text { Terms]) OR heart failure[Title]) }\end{array}$} & 116 & 1 \\
\hline & $\begin{array}{l}\text { ID Search } \\
\# 1 \text { "heart failure" } \\
\# 2 \text { carnitine }\end{array}$ & $\begin{array}{l}\text { Hits } \\
\qquad \begin{array}{l}28578 \\
1705\end{array}\end{array}$ & & \\
\hline $\begin{array}{l}\text { Cochrane } \\
\text { Library }\end{array}$ & $\begin{array}{l}\text { \#3 MeSH descriptor: [Carnitine] explode all trees } \\
\text { \#4 MeSH descriptor: [Heart Failure] explode all trees } \\
\text { \#5 \#2 OR \#3 } \\
\text { \#6 \#4 AND \#6 }\end{array}$ & $\begin{array}{ll}606 & \\
8482 & \\
1719 & \\
& 18\end{array}$ & 18 & 0 \\
\hline $\begin{array}{l}\text { Wiley } \\
\text { Online } \\
\text { Library }\end{array}$ & "carnitine" AND "heart failure" in Keywords & & 6 & 0 \\
\hline
\end{tabular}

Table 2. Study characteristics

\begin{tabular}{|c|c|c|c|c|c|c|c|c|}
\hline 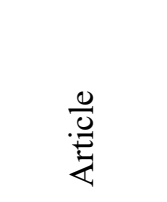 & 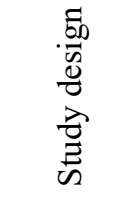 & 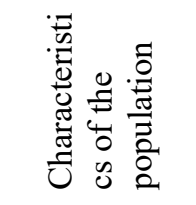 & 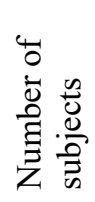 & 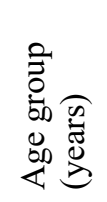 & 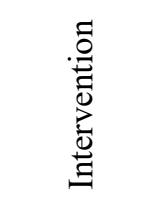 & 芯 & 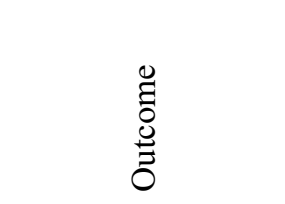 & 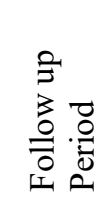 \\
\hline $\begin{array}{l}\text { Song } X \text {, et } \\
\text { al }(2017)^{11}\end{array}$ & $\begin{array}{c}\text { Meta } \\
\text { analysis }\end{array}$ & $\begin{array}{l}\text { Patients with } \\
\text { heart failure }\end{array}$ & 1625 & $43-78$ & $\begin{array}{l}\text { Carnitine } \\
1-6 \text { grams }\end{array}$ & $\begin{array}{l}\text { Without } \\
\text { carnitine }\end{array}$ & $\begin{array}{c}\text { Functional } \\
\text { capacity, heart } \\
\text { function, BNP and } \\
\text { NT-proBNP level, } \\
\text { side effects }\end{array}$ & $\begin{array}{c}7 \text { days } \\
\text { up to } 3 \\
\text { yeras }\end{array}$ \\
\hline
\end{tabular}

Table 3. Validity criteria

\begin{tabular}{|c|c|c|c|c|c|c|c|c|c|c|}
\hline \multirow{2}{*}{$\begin{array}{l}\text { Validity } \\
\text { Artikel }\end{array}$} & \multicolumn{10}{|c|}{ Relevance } \\
\hline & 苂 & 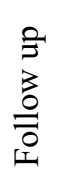 & 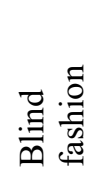 & 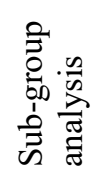 & $\begin{array}{l}\text { Ẽ } \\
\text { : } \\
\stackrel{0}{0}\end{array}$ & $\begin{array}{l}0 \\
\frac{\mathscr{n}}{0} \\
\stackrel{0}{2} \\
0\end{array}$ & $\frac{\frac{2}{2}}{\frac{2}{2}}$ & 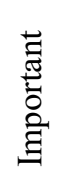 & Result & $\begin{array}{l}\text { Level of } \\
\text { Evidence }\end{array}$ \\
\hline $\begin{array}{l}\text { Song } X \text {, et al } \\
(2017)^{11}\end{array}$ & + & + & $-*$ & + & + & + & + & + & $\mathbf{A}$ & 1 \\
\hline
\end{tabular}

* Only 3 journals stated that there was blinding in patients and study members

Tabel 4. Relevance criteria

\begin{tabular}{lllll}
\hline Article & & Similarity Population & $\begin{array}{l}\text { Similarity } \\
\text { intervention/ indicators }\end{array}$ & Similarity Outcome \\
\hline $\begin{array}{l}\text { Song X, et } \\
(2017)^{11}\end{array}$ & & al + & + & + \\
\hline
\end{tabular}




\section{Conflict of interest}

The authors declare no conflict of interest regarding this study.

\section{Open Access}

This article is distributed under the terms of the Creative Commons Attribution 4.0 International Licence

(http://creativecommons.org/licenses/by/4.0/), which permits unrestricted use, distribution, and reproduction in any medium, provided you give appropriate credit to the original author(s) and the source, provide a link to the Creative Commons license, and indicate if changes were made.

\section{References}

1. World Health Organization. Regional Office for the Western Pacific. The Asia-Pacific perspective : redefining obesity and its treatment. Sydney: Health Communications Australia; 2000. Available from: https://apps.who.int/iris/handle/10665/206936.

2. Ambrosy AP, Fonarow GC, Butler J, Chioncel O, Greene SJ, Vaduganathan M, et al. The global health and economic burden of hospitalizations for heart failure: lessons learned from hospitalized heart failure registries. J Am Coll Cardiol 2014;63:112333.

3. Reyes EB, Ha JW, Firdaus I, Ghazi AM, Phrommintikul A, Sim D, et al. Heart failure across Asia: Same healthcare burden but differences in organization of care. Int J Cardiol 2016;223:163-7.

4. Wang ZY, Liu YY, Liu GH, Lu HB, Mao CY. 1Carnitine and heart disease. Life Sci 2018;194:8897.

5. Borum PR. Carnitine in parenteral nutrition. Gastroenterology 2009;137:S129-34.
6. Lapillonne A, Fidler Mis N, Goulet $\mathrm{O}$, van den Akker CHP, Wu J, Koletzko B, et al. ESPGHAN/ESPEN/ESPR/CSPEN guidelines on pediatric parenteral nutrition: Lipids. Clin Nutr 2018;37:2324-36.

7. Kinuagasa Y, Hirai M, Yanagihara K, Haruki N, Matsubara K, Kato M, et al. Carnitine Paradox in Patients With Heart Failure. Journal of Cardiac Failure 2017;23

8. Writing Committee M, Yancy CW, Jessup M, Bozkurt B, Butler J, Casey DE, Jr., et al. 2013 ACCF/AHA guideline for the management of heart failure: a report of the American College of Cardiology Foundation/American Heart Association Task Force on practice guidelines. Circulation 2013;128:e240-327.

9. Jing Z-C, Wu B-X, Peng J-Q, Li X-L, Pan L, Zhao $\mathrm{S}-\mathrm{P}$, et al. Effect of intravenous 1-carnitine in Chinese patients with chronic heart failure. European Heart Journal Supplements 2016;18:A27-A36.

10. Shang R, Sun Z, Li H. Effect dosing of L-carnitine in the secondary prevention of cardiovascular disease: a systematic review and meta-analysis. BMC Cardiovascular Disorders 2014;14:88.

11. Song X, Qu H, Yang Z, Rong J, Cai W, Zhou H. Efficacy and Safety of L-Carnitine Treatment for Chronic Heart Failure: A Meta-Analysis of Randomized Controlled Trials. Biomed Res Int 2017;2017:6274854.

12. Anand IS, Fisher LD, Chiang YT, Latini R, Masson $\mathrm{S}$, Maggioni AP, et al. Changes in brain natriuretic peptide and norepinephrine over time and mortality and morbidity in the Valsartan Heart Failure Trial (Val-HeFT). Circulation 2003;107:1278-83. 